\title{
Comparison of Plasma Ionization- and Secondary Electrospray Ionization- High-resolution Mass Spectrometry for Real-time Breath Analysis
}

\author{
Jiafa Zeng, ${ }^{\text {ab }}$ Alexandra Christen, ${ }^{\mathrm{c}}$ Kapil Dev Singh, ${ }^{\text {ab }}$ Urs Frey, ${ }^{\text {ab }}$ and Pablo Sinues ${ }^{\star a}$
}

\begin{abstract}
Real-time breath analysis by high-resolution mass spectrometry (HRMS) is a promising method to noninvasively retrieve relevant biochemical information. In this work, we conducted a head-to-head comparison of two ionization techniques: Secondary electrospray ionization (SESI) and plasma ionization (PI), for the analysis of exhaled breath. Two commercially available SESI and PI sources were coupled to the same HRMS device to analyze breath of two healthy individuals in a longitudinal study. We analyzed 58 breath specimens in both platforms, leading to 2,209 and 2,296 features detected by SESI-HRMS and by PI-HRMS, respectively. $60 \%$ of all the mass spectral features were detected in both platforms. However, remarkable differences were noted in terms of the signal-to-noise ratio $(\mathrm{S} / \mathrm{N})$, whereby the median (interquartile range, IQR) $\mathrm{S} / \mathrm{N}$ ratio for SESI-HRMS was $115(I Q R=408)$, whereas for PI-HRMS it was $5(I Q R=5)$. Differences in the mass spectral profiles for the same samples make the inter-comparability of both techniques problematic. Overall, we conclude that both techniques are excellent for real-time breath analysis because of the very rich mass spectral fingerprints. However, further work is needed to fully understand the exact metabolic insights one can gather using each of these platforms.
\end{abstract}

Keyworks: Breath analysis · Mass spectrometry · Plasma ionization · Secondary electrospray ionization.

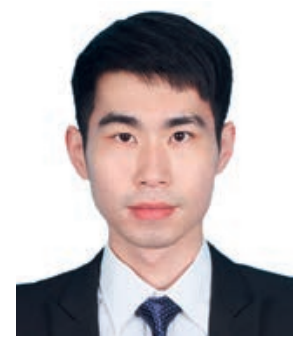

Jiafa Zeng obtained his Master's degree in Environmental Science from Jinan University (China), his research focused on the application of secondary electrospray ionization mass spectrometry (SESIMS) in environmental samples. Now he is a doctoral student in Prof. Pablo Sinues' research group in Department of Biomedical Engineering, University of Basel (Switzerland) since 2020, and working on the Exhaled Breath Analysis by SESI-MS in Children and Adolescents (EBECA) project.

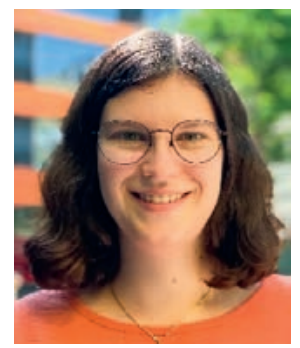

Alexandra Christen studied Life Sciences at University of Applied Sciences and Arts Northwestern in Muttenz, Switzerland, where she obtained her bachelor's degree in chemistry in 2021. After regular school education, she completed her apprenticeship as a chemical laboratory assistant at Paul Scherrer Institute in 2018. She chose instrumental analytics as her specialization and investigated the differences between two ion sources for real-time breath analysis with mass spectrometry in her bachelor's thesis at the University Children's hospital Basel (UKBB).

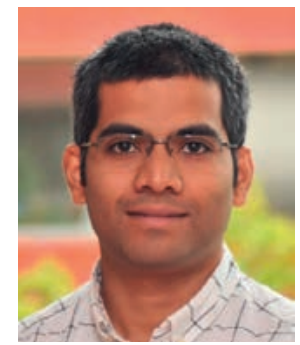

Kapil Dev Singh received his $\mathrm{PhD}$ degree in Molecular Life Sciences from University of Zurich (Switzerland). $\mathrm{He}$ is a senior scientist in the research group of Prof. Pablo Sinues at the Department of Biomedical Engineering, University of Basel.

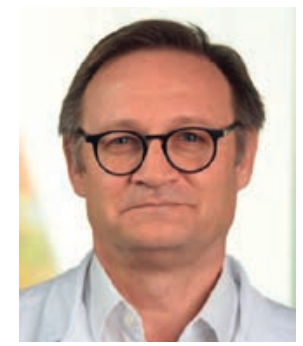

Urs Frey received his $\mathrm{PhD}$ degree in Bioengineering from the Leicester University (U.K.). Prof. Frey is the Medical Director, Chair of Pediatrics, University Children's Hospital, Basel. He is the leader of the pulmonology research group which is fundamentally interested in lung physiology and the epidemiology of lung growth and development, with a particular focus on bronchial asthma and chronic lung disease of infancy, as well as other wheezing disorders in infants and preschool children. 


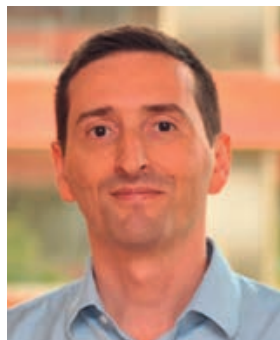

Pablo Sinues received his $\mathrm{PhD}$ degree in Mechanical Engineering from the Carlos III University of Madrid (Spain) and Habilitation in Analytical Chemistry at ETH Zurich. He is tenure-track assistant professor at the Department of Biomedical Engineering at the University of Basel (Basel, Switzerland) and lecturer at the Department of Chemistry and Applied Biosciences at ETH Zürich. Prof. Sinues heads the Translational Breath Research group located at the University Children's Hospital Basel.

\section{Introduction}

Human breath contains a wealth of metabolic information with translational potential. ${ }^{[1]}$ One success story in this context is fractional exhaled nitric oxide (FeNO), which is measured routinely to assess airway inflammation and to guide treatment therapy. ${ }^{[2]}$ However, despite the obvious attractiveness of breath analysis, just a handful of clinical breath tests are available. For this reason, further research, instrumentation development and clinical validations are needed to fully exploit the potential of breath analysis.

Secondary electrospray ionization - high-resolution mass spectrometry (SESI-HRMS) is a powerful tool for volatile organic compound analysis. ${ }^{[1,3]}$ SESI-HRMS allows for real-time breathprinting by detection of trace metabolites without any sample pretreatment. Regarding its ionization mechanism, it remains to be fully understood. However, atmospheric pressure gas-phase ion chemistry via ion switching plays a fundamental role.[4]

Plasma ionization (PI), or so-called dielectric barrier discharge ionization (DBDI), ${ }^{[5]}$ is also a real-time ionization technology. In terms of its sensitivity, it has shown absolute gas phase detection limits in the low ppt range, which is comparable to SESI. ${ }^{[6]}$

The plasma is generated through a discharge of dielectric barrier, subsequently, the plasma ionizes water vapor present in the atmosphere to produce $\mathrm{H}_{3} \mathrm{O}^{+}$and $\mathrm{OH}^{-}$, which in turn ionize the analytes in a soft way by proton transfer reaction. In addition, other reactive species $\left(\right.$ e.g. $\mathrm{O}^{+*}, \mathrm{NO}^{+}, \mathrm{CO}_{2}^{+\bullet},\left(\mathrm{H}_{2} \mathrm{O}\right) \mathrm{H}_{3} \mathrm{O}^{+}, \mathrm{N}_{2}^{+\bullet}, \mathrm{N}_{2} \mathrm{H}^{+}$ etc.) can be observed during the plasma ionization by introducing different discharge gases (e.g. air, $\mathrm{CO}_{2}$, humidified $\mathrm{N}_{2}$, etc.). ${ }^{[7]}$

While the virtues of SESI-HRMS for real-time breath analysis have been widely documented, ${ }^{[8]}$ those of PI-HRMS remain largely to be evaluated. ${ }^{[9]}$ In this paper, we make a contribution to this end by providing a head-to-head comparison between these two techniques. Our main goal was to understand to what extent both techniques can be complementary for real-time breath analysis.

\section{Methods}

\subsection{Mass Spectrometric Breath Measurements}

This study took place at the University Children's Hospital Basel following a similar procedure as described previously. ${ }^{[10]}$ The mass spectrometric breath analysis platform consisted of a Q-Exactive Plus (Thermo Fisher Scientific, Germany) coupled to either a SESI source (SuperSESI, FIT, Spain; Fig. 1a) or a PI source (SICRIT, Plasmion, Germany; Fig. 1b). The instrumental settings for both sources were tuned as instructed by the commercial providers.

PI: sampling line temperature $160^{\circ} \mathrm{C}$; frequency $12,000 \mathrm{~Hz}$; voltage $1.7 \mathrm{kV}$.

SESI: Sampling line temperature $130^{\circ} \mathrm{C}$; spray voltage $3.5 \mathrm{kV}$; electrospray reservoir pressure 1.3 bar; $20 \mu \mathrm{m}$ capillary; mass flow controller set point $0.9 \mathrm{~L} / \mathrm{min}$. In addition, in the case of the SESI set-up, an interface detecting exhaled $\mathrm{CO}_{2}$ and pressure (Exhalion, FIT, Spain) was used upstream the SESI source.

Two healthy individuals (a 22-year-old female with BMI of
22, and a 28-year-old male with BMI of 20.2) participated in this study. Each of them provided 58 breath samples over the course of two months (i.e. 29 samples for each ion source) with a weekly frequency of 1-5 measurements during working hours. Regarding the protocol, the participants were asked not to brush their teeth or eat or drink (except water), and not to use cosmetics and lipstick at least one hour before the measurement. In order to maximize the comparability between the two ion sources, the breath samples were provided nearly simultaneously (i.e. within $\sim 40$ minutes required to exchange sources and stabilization). Thus, parallel breath measurements were acquired in positive and negative ion mode for both ion sources and six replicate exhalations were provided for each ion mode. This study was approved by the Ethics Committee for Northwest/Central Switzerland (Analysis of Expired Breath by Secondary Electrospray Ionization-Mass Spectrometry (DOPAEx): a Pilot Study. Project ID: 2018-01324). All participants signed an informed consent form.

Prior to the breath measurements, the sensitivity of the instrument was checked with an external gas standard ( $\alpha$-terpinene at $100 \mathrm{ppb}$ | Dalian Special Gases Co. Ltd, Dalian, China) ${ }^{[11]}$ in the same cylinder for both platforms. Historical data on the same gas standard was used to confirm whether the instruments' performance was within the expected range using the so-called Nelson rules in process control.[12]
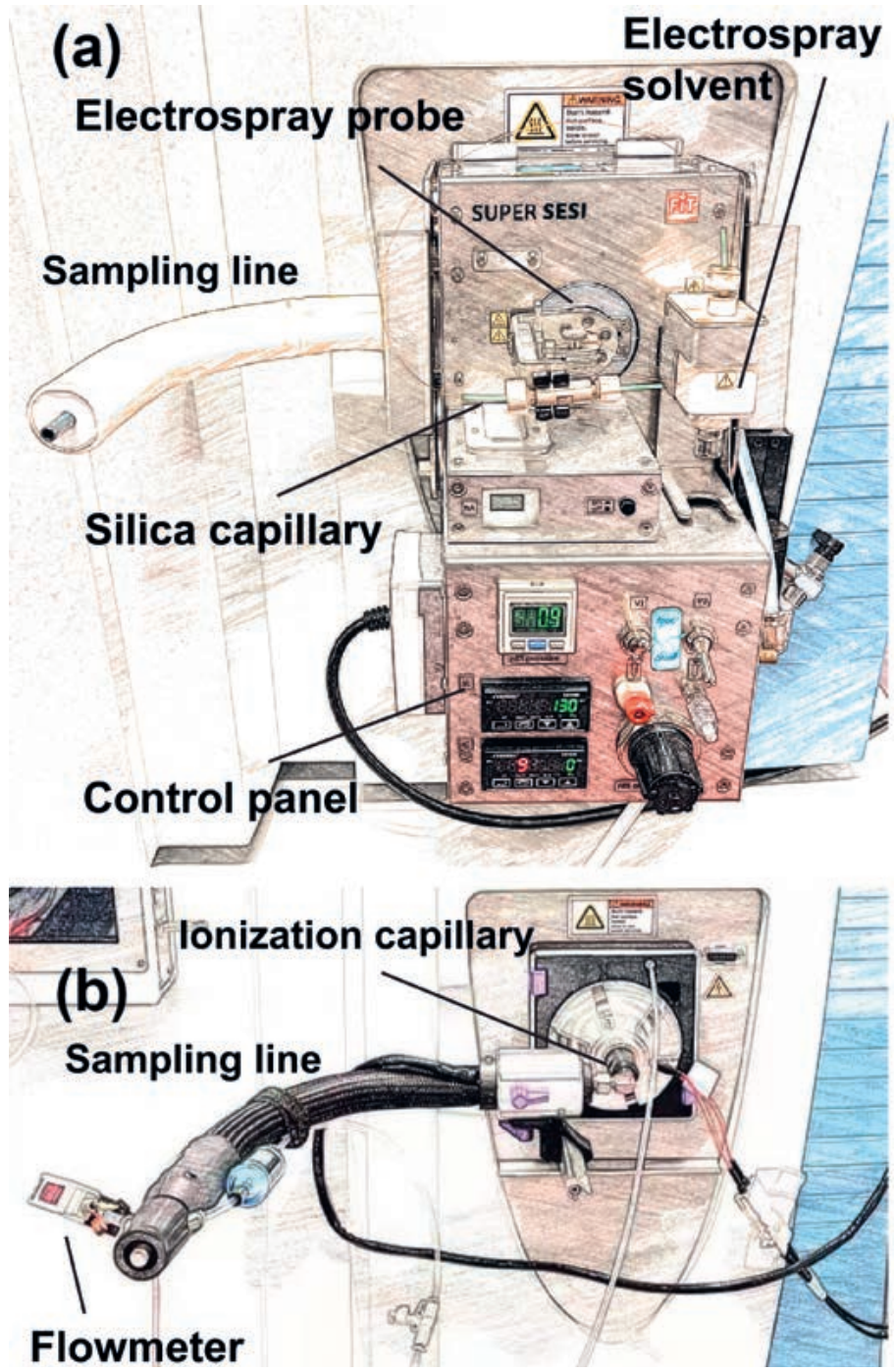

Fig. 1. Real-time breath analysis platforms. Schematic of SESI-HRMS (a) and PI-HRMS (b) 


\subsection{Data Analysis}

Data analysis was pursued in a MATLAB (version 2020b, MathWorks Inc., USA) and C\# environment. In brief, the MS raw files were accessed by in-house C\# console apps based on Thermo Fisher Scientific's RawFileReader (version 5.0.0.38). Time traces for each mass spectrometric feature were extracted. Exhalation events within each file were identified (i.e. six replicate exhalations per file) and the area under the curve (AUCs) during these time windows were integrated numerically. The background signal intensity was computed by integrating the area under the curve outside the exhalation events. AUCs were normalized by the width of the time window. Fig. S1 in the Supplementary Information shows an example of such time traces for the detection of one species in both SESI and PI set-up. The final signal intensity for each feature was computed using the mean AUC of the six replicates measurements. We further considered mass spectral features detected in at least $30 \%$ of the samples for each set of experiments done with SESI and PI. As a result, the SESI-HRMS data matrix contained 58 samples $\times 2,206$ features and PI-HRMS, 58 samples $\times 2,296$ features. In order to symmetrize the data distribution, the data were fifth root transformed.

\section{Results and Discussion}

\subsection{Quality Control with Gas Standard}

Fig. 2 shows representative mass spectra of $\alpha$-terpinene $\left(\mathrm{C}_{10} \mathrm{H}_{16}\right)$ gas standard detected by PI-HRMS (top) and SESI-HRMS (bottom). The base peak of the latter is the $[\mathrm{M}+\mathrm{H}]^{+}$ion, which is typically the case of SESI ionization. ${ }^{[4,13]}$ A labile molecule like this terpene leads to an in-source fragment at $m / z$ 81. ${ }^{[14]}$ Minor contributions of $[\mathrm{M}+\mathrm{OH}]^{+}$and $\left[\mathrm{M}+\mathrm{O}_{2} \mathrm{H}\right]^{+}$were also observed, suggesting that other ionization mechanisms may take place besides the noted ligand switching. In contrast, PI leads to the $[\mathrm{M}+\mathrm{OH}]^{+}$ion as base peak, followed by $[\mathrm{M}+\mathrm{H}]^{+}$at about $30 \%$ signal intensity of the base peak. PI is known to display a broad palette of gas-phase ion chemistry reactions. One plausible explanation for the formation of the dominant $[\mathrm{M}+\mathrm{OH}]^{+}$is that ambient $\mathrm{CO}_{2}$ becomes excited in the plasma to form the reactive species $\mathrm{CO}_{2}^{2}{ }^{+}$. Under these conditions, the analytes undergo further oxidation to ultimately form $[\mathrm{M}+\mathrm{OH}]^{+}$ions..$^{[15]}$ The third most abundant peak was $\left[\mathrm{C}_{10} \mathrm{H}_{15}\right]^{+}$. This is the $[\mathrm{M}-\mathrm{H}]^{+}$ion that can be produced by two different pathways:[15a] 1) by direct hydride abstraction reaction of the analyte $(\mathrm{M})$ with $\mathrm{CO}_{2}^{+\bullet}$ that produces $[\mathrm{M}-\mathrm{H}]^{+}$and $\mathrm{CO}_{2} \mathrm{H}^{*}$; or 2) by a water loss from the $[\mathrm{M}+\mathrm{OH}]^{+}$ion. Overall, the $[\mathrm{M}+\mathrm{H}]^{+}$signal intensity was approximately six times higher in SESI than in PI. This is one major advantage of SESI noted in this study as it favors mass spectral interpretability.

We further investigated the reproducibility of both systems towards the gas standard at $100 \mathrm{ppb}$. To do so, we also calculated the coefficient of variation $(\mathrm{CV})$ of the signal intensity of $[\mathrm{M}+\mathrm{H}]^{+}$ $\alpha$-terpinene with SESI-HRMS and the signal intensity of $[\mathrm{M}+\mathrm{OH}]^{+}$ ion with PI-HRMS during the two months that the measurements lasted (14 data points in total, Fig. S2). We found excellent and similar CVs for both techniques $(2.4 \%$ for SESI and $2.6 \%$ for PI).

\subsection{Real-time Breath Analysis}

After the analysis of 58 breath samples from the two subjects, we found a similar number of mass spectral features for both techniques: 2,206 for SESI-HRMS, and 2,296 for PI-HRMS. Fig. $\mathrm{S} 3$ shows the mean (and 95\% confidence interval) of the number of features as a function of $\mathrm{m} / \mathrm{z}$. The curve shape was similar for both methods with a steep rising in the numbers of features with masses below $300 \mathrm{Da}$ (i.e. most volatile species) followed by slow growth for the heaviest species up to 1,000 Da. However, as indicated in Fig. 2, given the different nature of the ionization mechanisms, one should expect different features for a given species (i.e.

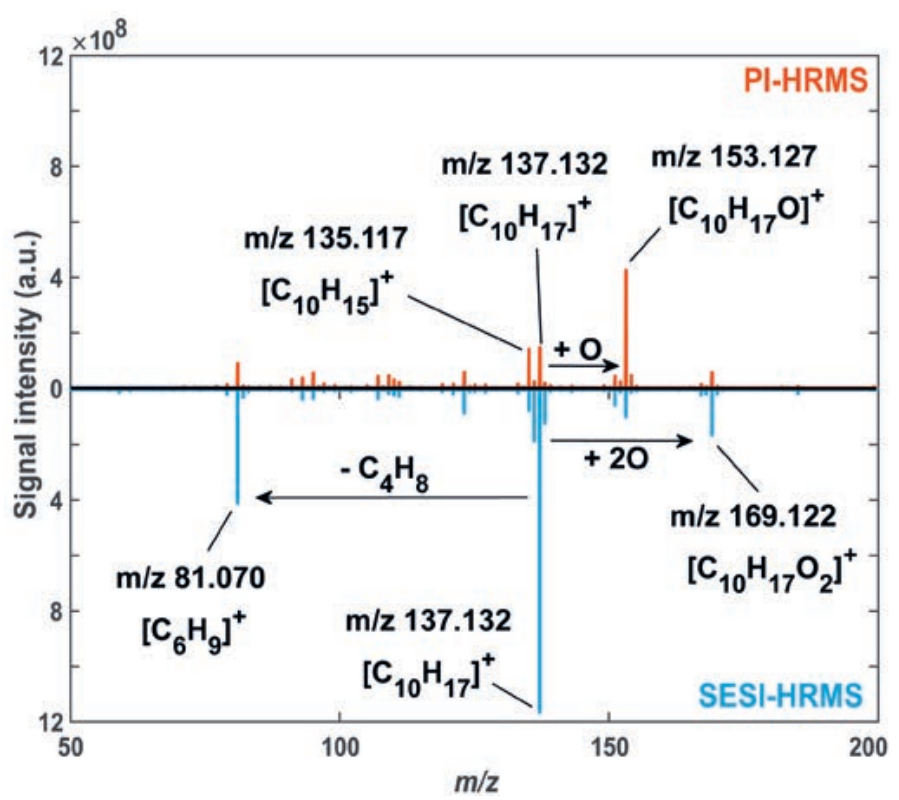

Fig. 2. The same analyte leads to different mass spectra. Mass spectra of terpinene $\left(\mathrm{C}_{10} \mathrm{H}_{16}\right)$ gas standard detected by PI-HRMS (top) and SESI-HRMS (bottom). The base peak of PI-HRMS is the [M+OH] $]^{+}$ion, followed by $[\mathrm{M}+\mathrm{H}]^{+}$and $[\mathrm{M}-\mathrm{H}]^{+}$ions at about $30 \%$ signal intensity of the base peak. SESI-HRMS detected protonated $[\mathrm{M}+\mathrm{H}]^{+}$ion as base peak, and an in-source fragment at $m / z$ 81. Minor contributions of $[\mathrm{M}+\mathrm{OH}]^{+}$ and $\left[\mathrm{M}+\mathrm{O}_{2} \mathrm{H}\right]^{+}$were also observed.

protonated/deprotonated species for SESI and oxidated species for PI). The overlap found between both techniques was in the order of $60 \%$ (1,339 common features; Fig. 3).

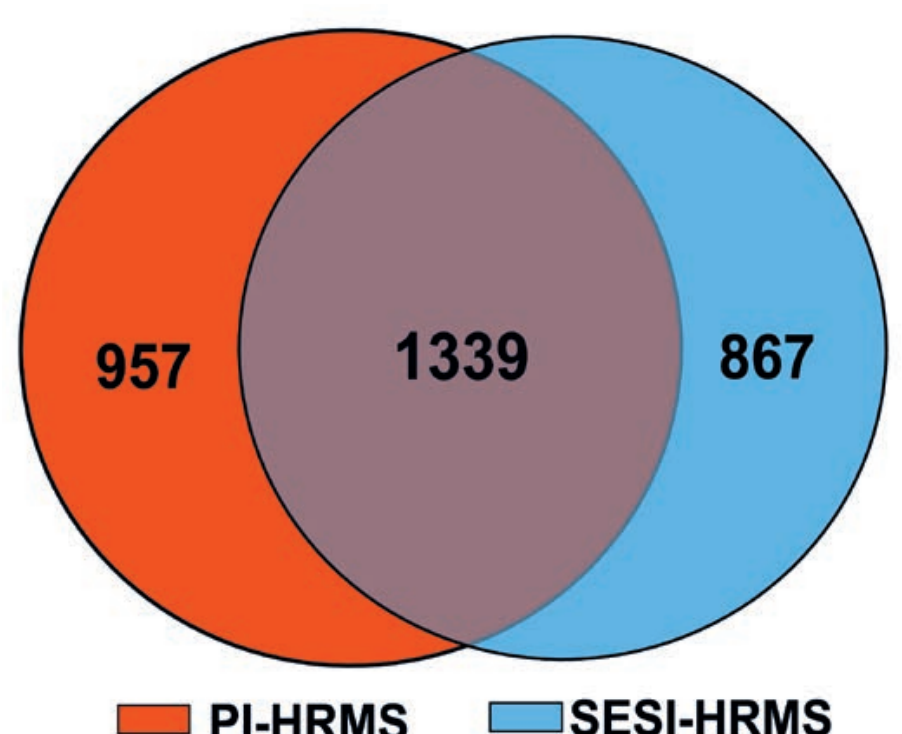

Fig. 3. Overlap of breath mass spectral features across platforms. A total of 2,206 features were detected by SESI-HRMS, and 2,296 features by PI-HRMS, with 1,339 features among them detected by both instruments.

The next question we addressed was the signal to noise $(\mathrm{S} / \mathrm{N})$ ratio of the detected features. In this case, SESI showed a more satisfactory result (Fig. 4), whereby $99 \%$ of the 1,339 common features showed a $\mathrm{S} / \mathrm{N}$ ratio $\geq 3$ and $86 \%$ of them $\geq 10$. In contrast, for PI, $79 \%$ of the common features had a $\mathrm{S} / \mathrm{N}$ ratio $\geq 3$ and just $21 \%$ of them $\geq 10$. The median (interquartile range, IQR) $\mathrm{S} / \mathrm{N}$ ratio 
for SESI-HRMS was 115 (408), whereas for PI-HRMS was 5 (5). The poorer S/N ratio generally found for PI could be attributed to an overall higher background signal intensity. Whether this is due to the different ion chemistry, to a generally less VOC-free background curtain-gas or a combination of both is currently unknown.

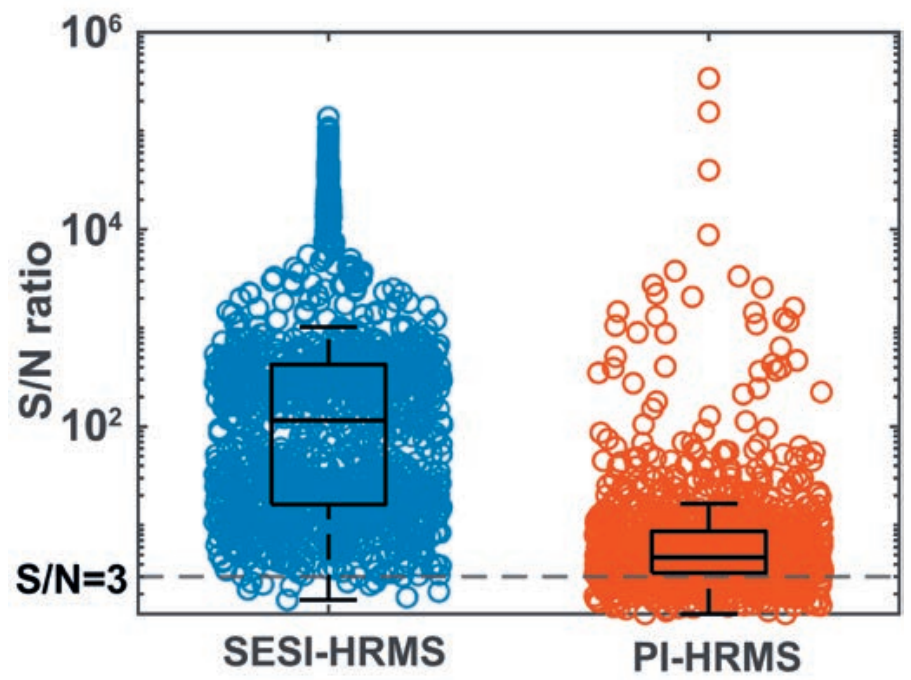

Fig. 4. SESI-HRMS shows a better off signal-to-noise $(\mathrm{S} / \mathrm{N})$ ratio. S/N ratio distribution of the 1,339 common features. Note the logarithmic scale. SESI-HRMS shows a more satisfactory result with a median S/N ratio of (IQR) 115 (408), whereas for PI-HRMS it was 5 (5).

Such disparity in the $\mathrm{S} / \mathrm{N}$ ratios and gas-phase ion-molecule reactions led to very significant differences between the breath mass spectra for the same individuals. This is illustrated in Fig. 5, which shows a principal component analysis score plot of the breath mass spectra (common features only) for the two subjects as measured by SESI- and PI-HRMS. Clearly, the first score (explaining $47 \%$ of the variance) separates the two platforms. Moreover, the ion with the highest loadings was found to be a common laboratory contaminant ${ }^{[16]}\left[\mathrm{C}_{16} \mathrm{H}_{52} \mathrm{O}_{8} \mathrm{NSi}_{8}\right]^{+}$(polysiloxane, $\mathrm{m} / \mathrm{z}$ 610.1827, $\left[\mathrm{M}+\mathrm{NH}_{4}\right]^{+}$; Fig. S4), which showed two orders of magnitude stronger intensity in PI-HRMS than SESI-HRMS. This clearly indicates that inter-comparability of the data in future clinical studies with both breath analysis platforms will be problematic.

Principal component 2 suggests capturing inter-individual differences. ${ }^{[17]}$ For example, the feature with the maximum loading in $\mathrm{PC} 2$ was $\left[\mathrm{C}_{4} \mathrm{H}_{11} \mathrm{O}_{3} \mathrm{~N}_{2}\right]^{-}(\mathrm{m} / \mathrm{z}$ 135.0788, Fig. S5) and was found to be systematically more abundant for subject 2 in both platforms.

In addition to these common features, we found nearly a thousand ions that were only detected by PI-HRMS or SESIHRMS. During the next phase of the analysis, we concentrated on this set of signals to better understand the differences between the two ion sources for real-time breath analysis. To this end, we used Kendrick mass defect (KMD) ${ }^{[18]}$ plots and Van Krevelen diagrams ${ }^{[19]}$ to gather further insights into whether specific families or homologous series could be covered by one technique but not by the other.

The KMD plot of positive-odd $\mathrm{m} / \mathrm{z}$ is shown in Fig. 6 . It shows a broad overlapping region of homologous series (black dots), including 4-hydroxy-2-alkenals $\left(\mathrm{C}_{\mathrm{n}} \mathrm{H}_{2 \mathrm{n}-2} \mathrm{O}_{2}\right)$ and 4-hydroxy-2,6-alkadienals $\left(\mathrm{C}_{\mathrm{n}} \mathrm{H}_{2 \mathrm{n}-4} \mathrm{O}_{2}\right) \cdot{ }^{20]}$ Please note that these $[\mathrm{M}+\mathrm{H}]^{+}$assignments have been confirmed by SESI-HRMS, but not by PI-HRMS. In fact, as shown in Fig. 2, it could well be

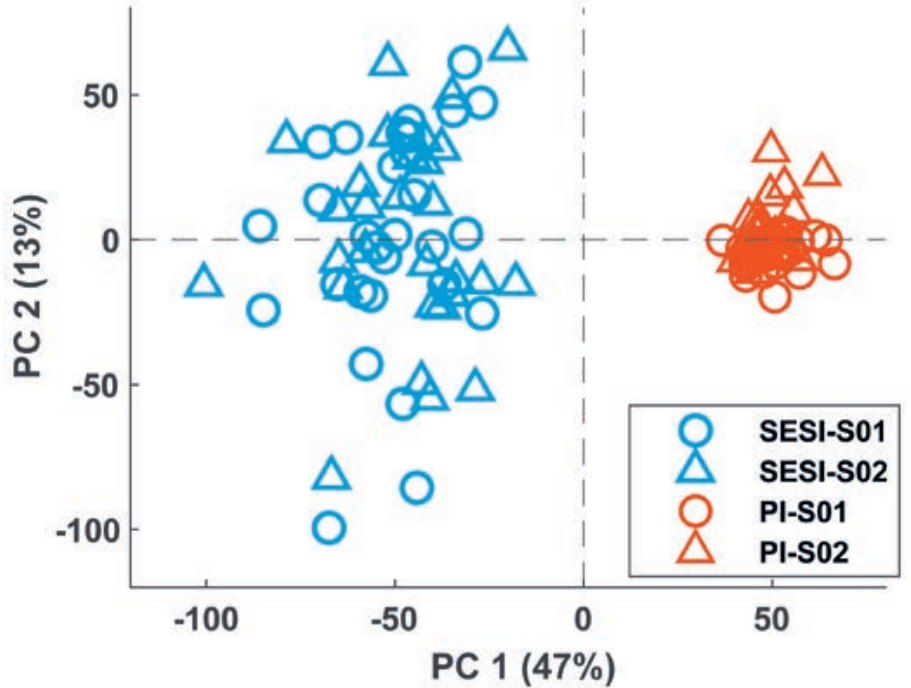

Fig. 5. Inter-platform comparability remains a challenge. PCA score plot of the two subjects by as measured by the two instruments (common features only). The clustering according to ion source along the first PC reveals a very different response towards the same samples.

that such ions correspond to other metabolites (e.g. detected as $\left.[\mathrm{M}+\mathrm{OH}]^{+}\right)$, as protonation is just one of the mechanisms by which PI leads to ionized species. In other words, the overlap at the $\mathrm{m} / \mathrm{z}$, level does not imply an overlap at the molecule level. On the righthand side, one can observe complete series of highly oxygenated species such as $\mathrm{C}_{n} \mathrm{H}_{2 n-10} \mathrm{O}_{4}$ and $\mathrm{C}_{\mathrm{n}} \mathrm{H}_{2 \mathrm{n}-10} \mathrm{O}_{5}$ series detected only by PI-HRMS. Again, it is unclear at this point whether these correspond to unique metabolites detectable only by PI-HRMS, or just molecules detected as protonated ions by SESI-HRMS and as $\left[\mathrm{M}+\mathrm{O}_{\mathrm{x}} \mathrm{H}\right]^{+}$by PI-HRMS. Fig. 6 highlights again the difficulty to intercompare both datasets if future metabolomics studies aim to use both techniques simultaneously in multicenter studies.

Another observed singularity was a cloud of ions detected only by SESI-HRMS in the upper-left area of the KDM plot (Fig. 6). No molecular formulae fulfilling 'seven golden rules' ${ }^{21]}$ could be assigned to these features considering (de) protonated molecules containing $\mathrm{C}, \mathrm{H}, \mathrm{N}$ or $\mathrm{O}$. A total of 526 features remained unassigned in positive mode, out of which 163 features were found to have $\mathrm{m} / \mathrm{z}$ below the nominal mass $(e . g$. $\mathrm{m} / \mathrm{z}$ 134.9578), which tended to cluster together (e.g. clusters 2 and 3 in Fig. 7). These features were present in $30-40 \%$ of all the SESI-HRMS samples and were detected in both individuals. To gather further insights into a plausible origin of such ions, we computed the pairwise correlation for all 526 ions detected in positive mode. Strikingly, 349 features had $r \geq 0.95$ and clustered in 50 networks (Fig. 7). The largest network, network (1) in Fig. 7 and Table S1, contained a staggering number of 190 features. Further analysis of the correlation networks suggests likely insource fragmentation, resulting in loss of $\mathrm{CH}_{2}, \mathrm{CO}, \mathrm{OH}$ or $\mathrm{H}_{2} \mathrm{O}$. For example, $m / z, 200.9129$ in network 3 is probably produced by the loss of water from $\mathrm{m} / \mathrm{z}$ 218.9234. Subsequent further water loss leads to $\mathrm{m} / \mathrm{z}, 200.9129$ and $\mathrm{m} / \mathrm{z} 182.9024$. At the center of the network 3 are $m / z 198.9122$ and $m / z$ 180.9016, which again differ by one $\mathrm{H}_{2} \mathrm{O}$ group. While the process leading to such redundant information remains unknown, it highlights the importance of interpreting SESI-HRMS spectra carefully. As noted recently, other important factors beyond the recognized gas-phase ligand switching mechanism may play a significant role.[4b,c]

Some other clusters can be simply assigned to isotopic features, which obviously display a high correlation. For example, cluster 6 corresponds to protonated benzothiazole,[22] whereby $\mathrm{m} / \mathrm{z} 137.0209$ corresponds to $\left[\mathrm{C}_{7} \mathrm{H}_{6} \mathrm{~N}^{33} \mathrm{~S}\right]^{+} ; \mathrm{m} / \mathrm{z}, 137.0248$ corresponds to $\left[\mathrm{C}_{6}{ }^{13} \mathrm{CH}_{6} \mathrm{~N}^{32} \mathrm{~S}\right]^{+}$and $\mathrm{m} / z, 138.0173$ corresponds to 


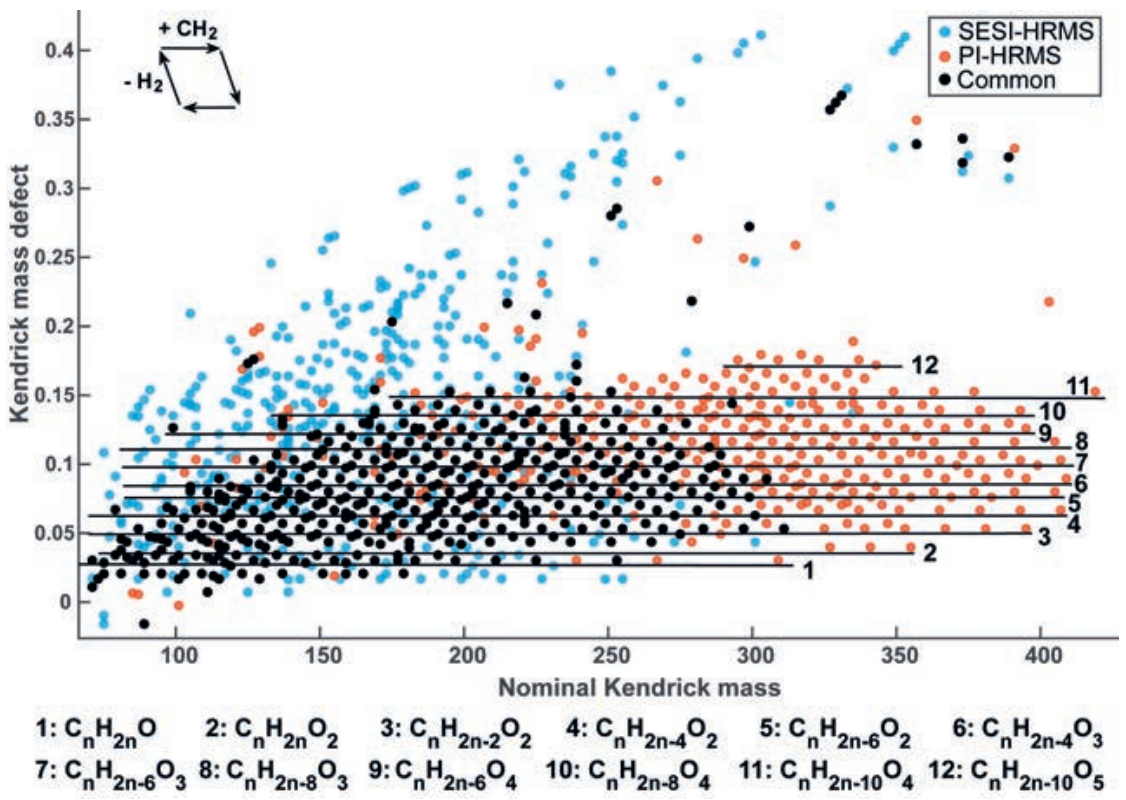

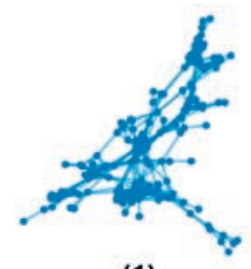

(1)

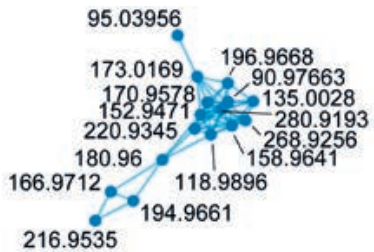

(2)

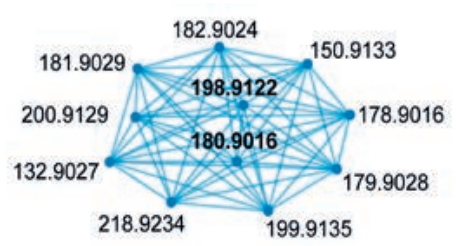

(3)

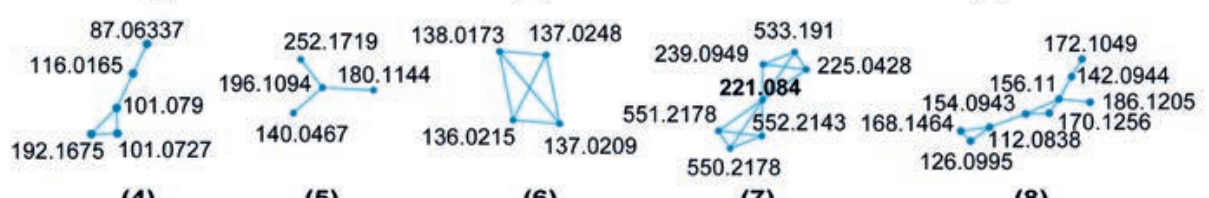

(4)

(5)
(7)
Fig. 6. Insights into common and unique homologous series detected by PI- and SESIHRMS. Kendrick Mass Defect plot of positive-odd $\mathrm{m} / \mathrm{z}$. Orange dots denote the ions detected exclusively by PI-HRMS, blue dots by SESI-HRMS and the black dots are overlapping features detected by both.
Fig. 7. SESI-HRMS leads to series of highly correlating features of largely unknown origin. Correlation network $(r>$ 0.95) of 349 features without assigned molecular formula detected by SESI-HRMS.

Common mass differences indicate losses of $\mathrm{CH}_{2}, \mathrm{CO}, \mathrm{OH}$ and $\mathrm{H}_{2} \mathrm{O}$, as well as carbon and sulfur isotopes.
(9)

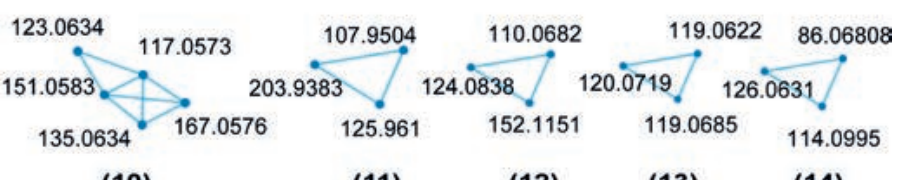

(11)
(12)

(13)

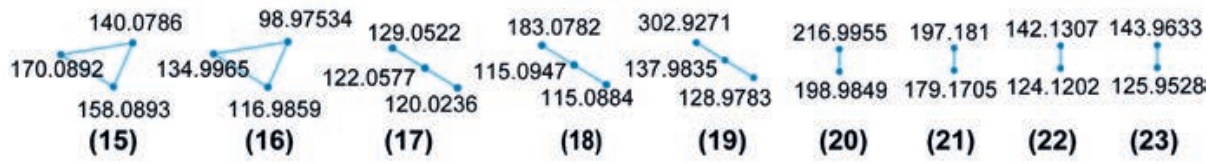

$\begin{array}{cccccccccc}128.1151 & 176.9845 & 182.9811 & 126.9657 & 155.0679 & 168.1144 & 170.162 & 192.0842 & 144.11 & 146.1369 \\ \vdots & \vdots & \vdots & \vdots & \vdots & \vdots & \vdots & \vdots & \vdots & \vdots\end{array}$ $\begin{array}{llllllllll}110.1045 & 158.9739 & 164.9707 & 124.9665 & 127.0728 & 110.0726 & 152.1515 & 178.0685 & 130.0944 & 118.1056\end{array}$
(24)
(25)
(26)
(27)
(28)
(29)
(30)
(31)
(32)
(33)

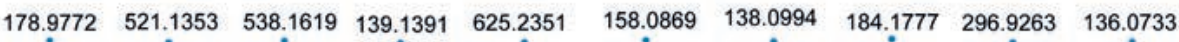

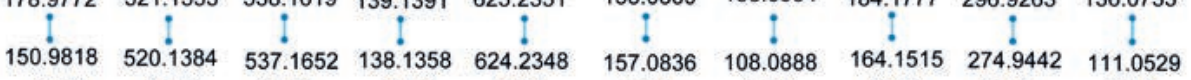
(34)
(35)
(36)
(37) (38)
(39)
(40)
(41)
(42)
(43)

$\begin{array}{lcccccc}133.0794 & 251.0001 & 136.0838 & 214.1882 & 141.0145 & 75.09976 & 90.07428 \\ \vdots & \vdots & \vdots & \vdots & \vdots & \vdots & \vdots \\ 88.02151 & 98.98413 & 134.0681 & 156.0736 & 140.0305 & 75.09344 & 90.06796 \\ \mathbf{( 4 4 )} & \mathbf{( 4 5 )} & \mathbf{( 4 6 )} & \mathbf{( 4 7 )} & \mathbf{( 4 8 )} & \mathbf{( 4 9 )} & \mathbf{( 5 0 )}\end{array}$

$\left[\mathrm{C}_{7} \mathrm{H}_{6} \mathrm{~N}^{34} \mathrm{~S}\right]^{+}$. A similar KMD picture emerged for the analysis of Finally, in order to gain additional insights into the similarities even positive masses and negative ion mode (Fig. S6), whereby and differences of the ions detected by the two techniques under both techniques show overlapping homologous series, as well investigation, we visualized the data using a van Krevelen diagram as distinct features.
(Fig. S7). Briefly, all ions with an assigned elemental formula are 
projected onto two axes in the diagram according to its $\mathrm{H} / \mathrm{C}, \mathrm{O} / \mathrm{C}$ atomic ratios. The $\mathrm{H} / \mathrm{C}$ ratio separates compounds according to degree of saturation, whereas $\mathrm{O} / \mathrm{C}$ ratios separate according to $\mathrm{O}$ classes. Several classes of previously identified metabolites were added to the diagram in different colors as reference compounds. ${ }^{[20,23]}$ Most of them (except for amino acids) lie in the region $\mathrm{H} / \mathrm{C} \leq 2$ and $\mathrm{O} / \mathrm{C} \leq 2$. The figure reveals that a large fraction of the ions detected exclusively by PI-HRMS is distributed in this area, whereas those unique to SESI-HRMS tend to occupy the $\mathrm{O} / \mathrm{C} \leq 0.2$ space. Regarding oxygen content, $92 \%$ of the PI-HRMS features contain at least one oxygen atom, while for SESI-HRMS this figure was $85 \%$, consistent with the greater tendency of PI to generate oxidated species.

\section{Conclusion}

We have compared for the first time the performance of two commercially available PI-HRMS and SESI-HRMS systems for real-time analysis of human breath. We conclude that both techniques are suitable to detect thousands of mass spectral features without any sample pre-treatment. Around 1,300 of these features were detected simultaneously by both techniques. We found that the $\mathrm{S} / \mathrm{N}$ ratio for these features was overall substantially higher for SESI-HRMS. In addition, the overall analysis of this common set of features revealed a strong batch effect according to the platform used, indicating that the inter-comparability of data across platforms is problematic. The reason behind most likely lies in the very different ionization mechanisms of SESI and plasma, which for the same metabolites can lead to different ion species. While protonated/deprotonated species are common in SESI, PI can often lead to oxygenated species. Overall, we conclude that both platforms are most suitable for realtime breath analysis studies, although further research is needed to fully understand what kind of metabolic insights one can obtain with both platforms and to what extent they are complementary.

\section{Supplementary Information}

Supplementary information is available on https://www.chimia.ch

\section{Acknowledgements}

PS received funding from Fondation Botnar (Switzerland) and Swiss National Science Foundation (320030_173168 and PCEGP3_181300). Dr. Christian Berchtold (FHNW) is gratefully acknowledged for supporting the internship of $\mathrm{AC}$ at UKBB

Received: October 29, 2021

[1] H. Li, J. Zhu, J. E. Hill, Encyclopedia of Analytical Chemistry 2018 , https://doi.org/10.1002/9780470027318.a9607.

[2] R. A. Dweik, P. B. Boggs, S. C. Erzurum, C. G. Irvin, M. W. Leigh, J. O. Lundberg, A.-C. Olin, A. L. Plummer, D. R. Taylor, American Thoracic Society, Am. J. Respir. Crit. Care Med. 2011, 184, 602, https://doi.org/10.1164/rccm.9120-11ST.

[3] a) K. D. Singh, M. Osswald, V. C. Ziesenitz, M. Awchi, J. Usemann, L. L. Imbach, M. Kohler, D. García-Gómez, J. van den Anker, U. Frey, A. N. Datta, P. Sinues, Commun. Med. 2021, 1, https://doi.org/10.1038/s43856-021-00021-3; b) T. Bruderer, M. T. Gaugg, L. Cappellin, F. Lopez-Hilfiker, M. Hutterli, N. Perkins, R. Zenobi, A. Moeller, J. Am. Soc. Mass Spectrom. 2020, https://doi.org/10.1021/jasms.0c00059;

Li, M. Xu, J. Zhu, Anal. Chem. 2019, 91, 854 https://doi.org/10.1021/acs.analchem.8b03517; d) H. Li, J. Zhu, Anal. Chem. 2018, 90, 12108, https://doi.org/10.1021/acs.analchem.8b03029;e) J. H. J. Lee, J. Zhu, Metabolites 2020, 10, https://doi.org/10.3390/metabo10090351; f) F. Choueiry, J. Zhu, Anal. Chim. Acta 2022, 1189, 339230, https://doi.org/10.1016/j.aca.2021.339230; g) X. Li, D. Huang, J. Zeng, C. K. Chan, Z. Zhou, Talanta 2019, 192, 32, https://doi.org/10.1016/j.talanta.2018.09.020; h) X. Li, D. D. Huang, R. Du, Z. J. Zhang, C. K. Chan, Z. X. Huang, Z. Zhou, J. Vis. Exp. 2018, 2018, https://doi.org/10.3791/56465; i) L. Huang, X. Li, M. Xu, Z. Huang, Z. Zhou, Gaodeng Xиexiao Ниахие Xиebao/Chem. J. Chin. Uni. 2017, 38, 752, https://doi.org/10.7503/cjcu20160821.

[4] a) A. T. Rioseras, M. T. Gaugg, P. Martinez-Lozano Sinues, Anal. Meth. 2017, 9, 5052, https://doi.org/10.1039/c7ay01121k; b) K. Dryahina, M. Polasek, D. Smith, P. Spanel, Rapid Commun. Mass Spectrom. 2021, 35, e9187, https://doi.org/10.1002/rcm.9187; c) K. Dryahina, S. Som, D.
Smith, P. Spanel, Rapid Commun. Mass Spectrom. 2021, 35, e9047, https://doi.org/10.1002/rcm.9047

[5] M. Dumlao, P. M.-L. Sinues, M. Nudnova, R. Zenobi, Anal. Meth. 2014, 6 , https://doi.org/10.1039/c4ay00303a.

[6] J. C. Wolf, M. Schaer, P. Siegenthaler, R. Zenobi, Anal. Chem. 2015, 87, 723, https://doi.org/10.1021/ac5035874.

[7] L. Gyr, F. D. Klute, J. Franzke, R. Zenobi, Anal. Chem. 2019, 91, 6865, https://doi.org/10.1021/acs.analchem.9b01132.

[8] X.Li,L.Huang,H.Zhu,Z.Zhou,RapidCommun.MassSpectrom. 2017,31,301, https://doi.org/10.1002/rcm.7794

[9] L. Bregy, P. M. L. Sinues, M. M. Nudnova, R. Zenobi, J. Breath Res. 2014, 8, https://doi.org/10.1088/1752-7155/8/2/027102.

[10] K. D. Singh, G. Tancev, F. Decrue, J. Usemann, R. Appenzeller, P. Barreiro, G. Jauma, M. Macia Santiago, G. Vidal de Miguel, U. Frey, P. Sinues, Anal. Bioanal. Chem. 2019, 411, 4883, https://doi.org/10.1007/s00216-019-01764-8.

[11] C.Liu,J.F.Zeng,P.Sinues,M.L.Fang,Z.Zhou,X.Li,Anal.Chim.Acta 2021,1180, https://doi.org/10.1016/j.aca.2021.338876.

[12] L. S. Nelson, J. Qual. Technol. 1984, 16, 237 , https://doi.org/10.1080/00224065.1984.11978921.

[13] P. Martinez-Lozano Sinues, E. Criado, G. Vidal, Int. J. Mass spectrom. 2012, 313, 21, https://doi.org/10.1016/j.ijms.2011.12.010.

[14] A. Gisler, J. Lan, K. D. Singh, J. Usemann, U. Frey, R. Zenobi, P. Sinues, J. Breath Res. 2020, 14, 046001, https://doi.org/10.1088/1752-7163/ab9f8b.

[15] a) J. C. Wolf, L. Gyr, M. F. Mirabelli, M. Schaer, P. Siegenthaler, R. Zenobi, J. Am. Soc. Mass Spectrom. 2016, 27, 1468, https://doi.org/10.1007/s13361-016-1420-2; $\quad$ b) J. Syage, J. Am. Soc. Mass Spectrom. 2004, 15, 1521, https://doi.org/10.1016/j.jasms.2004.07.006.

[16] a) S. R. Kumbhani, L. M. Wingen, V. Perraud, B. J. FinlaysonPitts, Rapid Commun. Mass Spectrom. 2017, 31, 1659, https://doi.org/10.1002/rcm.7951; b) B. O. Keller, J. Sui, A. B. Young, R. M. Whittal, Anal. Chim. Acta 2008, 627, 71, https://doi.org/10.1016/j.aca.2008.04.043; c) A. Schlosser, R. Volkmer-Engert, J. Mass Spectrom. 2003, 38, 523, https://doi.org/10.1002/jms.465.

[17] P. M. L. Sinues, M. Kohler, R. Zenobi, PLoS One 2013, 8, https://doi.org/10.1371/journal.pone.0059909.

[18] L. Sleno, J. Mass Spectrom. 2012, 47, 226 , https://doi.org/10.1002/jms.2953.

[19] S. Kim, R. W. Kramer, P. G. Hatcher, Anal. Chem. 2003, 75, 5336, https://doi.org/10.1021/ac034415p.

[20] D. García-Gómez, P. Martínez-Lozano Sinues, C. Barrios-Collado, G. Vidal-De-Miguel, M. Gaugg, R. Zenobi, Anal. Chem. 2015, 87, 3087, https://doi.org/10.1021/ac504796p.

[21] T. Kind, O. Fiehn, BMC Bioinformatics 2007, 8, 105, https://doi.org/10.1186/1471-2105-8-105.

[22] D. Garcia-Gomez, L. Bregy, Y. Nussbaumer-Ochsner, T. Gaisl, M. Kohler, R. Zenobi, Environ. Sci. Technol. 2015, 49, 12519, https://doi.org/10.1021/acs.est.5b03809.

[23] a) M. T. Gaugg, A. Engler, L. Bregy, Y. Nussbaumer-Ochsner, L. Eiffert, T. Bruderer, R. Zenobi, P. Sinues, M. Kohler, Respirology 2019, 24, 437, https://doi.org/10.1111/resp.13465; b) D. Garcia-Gomez, T. Gaisl, L. Bregy, P. Martinez-ozano Sinues, M. Kohler, R. Zenobi, Chem. Commun. (Camb) 2016, 52, 8526, https://doi.org/10.1039/c6cc03070j; c) A. Tejero Rioseras, K. D. Singh, N. Nowak, M. T. Gaugg, T. Bruderer, R. Zenobi, P. M. Sinues, Anal. Chem. 2018, 90, 6453, https://doi.org/10.1021/acs.analchem.7b04600; d) M. T. Gaugg, T. Bruderer, N. Nowak, L. Eiffert, P. Martinez-Lozano Sinues, M. Kohler, R. Zenobi, Anal. Chem. 2017, 89, 10329, https://doi.org/10.1021/acs.analchem.7b02092; e) P. MartinezLozano, J. F. de la Mora, Anal. Chem. 2008, 80, 8210, https://doi.org/10.1021/ac801185e.

\section{License and Terms}

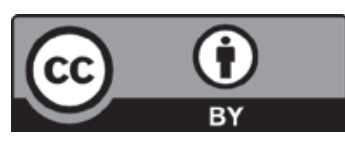

This is an Open Access article under the terms of the Creative Commons Attribution License CC BY 4.0. The material may not be used for commercial purposes.

The license is subject to the CHIMIA terms and conditions: (https://chimia.ch/chimia/about).

The definitive version of this article is the electronic one that can be found at https://doi.org/10.2533/chimia.2022.127 